\title{
Extended TOPSIS model for solving multi-attribute decision making problems in engineering
}

\author{
Daniel O. Aikhuele ${ }^{a^{*}}$ and Faiz M. Turan ${ }^{\mathrm{a}}$
}

${ }^{a}$ Faculty of Manufacturing Engineering, Universiti Malaysia Pahang, Pekan, 26600, Pahang-Malaysia, Malaysia

\begin{tabular}{l}
\hline C H R O N I C L E \\
\hline Article history: \\
Received September 16, 2016 \\
Received in revised format: \\
October 22, 2016 \\
Accepted February 22, 2017 \\
Available online \\
February 222017 \\
\hline Keywords: \\
TOPSIS \\
Extended Topsis \\
Intuitionistic fuzzy TOPSIS
\end{tabular}

\section{Introduction}

Decision making processes which are widely used in engineering, management, economic, and in so many other fields are concerned with problems of prioritizing, screening, ranking or selecting alternative(s) from a finite set of candidates with multiple conflicting attributes, by considering them simultaneously to select the best candidates (Braglial et al., 2003). Since, decision-making information are often incomplete, inconsistent and indeterminate, the manner in which they are to be expressed has remained a major task among researchers, and has resulted in more and more interest in the topic over the past several years.

To handle these issues, Zadeh (1965), introduced the concept of fuzzy set theory, has outlined how the fuzzy set (FS) concept could be used for expressing such decision-making problems. But the FS theory which is characterized by only one membership function $\mu_{A}(x)$ cannot be used to express some kind

* Corresponding author.

E-mail address: danbishop_22@yahoo.co.uk (D. O. Aikhuele)

(C) 2017 Growing Science Ltd. All rights reserved.

doi: $10.5267 /$ j.dsl.2017.2.002 
of complex fuzzy information. 'For example, during voting, if there are ten persons voting for an issue, and three of them give the "agree", four of them give the "disagree", and the others abstain. Obviously, FS cannot fully express the polling information' (Liu \& Zhang, 2014).

To solve these kinds of complex fuzzy-based information issues, in 1986, Atanassov extended the FS theory by adding a non-membership function $v_{A}(x)$ to form the intuitionistic fuzzy set (IFS) theory (Atanassov, 1986). The IFS consists of the membership function $\mu_{A}(x)$ and non-membership function $v_{A}(x)$, and according to Saurav et al. (2013) and Wan and Li, (2015), the IFS are more flexible, practical and capable than the traditional FS theory for handling incomplete, inconsistent and indeterminate (vagueness and uncertainty) information in practice. The benefits of applying the IFS for decision-making was described in detail by Xu and Liao, (2015), and Xu et al. (2013) and in its many practical applications (Bai, 2013; Chen \& Chiou, 2015; Jahromi, 2012; Li, 2005; Lin et al., 2007; Liu \& Ren, 2014; Xu, 2014).

In order to make comparisons between two preference information that are expressed in IFS, some metric methods were introduced, that is the score functions and accuracy functions (Chen \& Tan, 1994; Hong \& Choi, 2000; Wu, 2015; Xu, 2007) which were applied for solving MADM problems. However, investigations of these functions show some vital shortcomings, according to $\mathrm{Wu}(2015)$ the results obtained using the score functions and accuracy functions are not always consistent, also they often produce negative priority vector in their applications. Although, the exponential score function later proposed by $\mathrm{Wu},(2015)$ as a remedy, appears to address these shortcomings, the function is only effective for determining priority weight that involves pairwise comparison. Therefore, in this paper, we propose a new exponential related function (ER) and develop an intuitionistic fuzzy TOPSIS model based on the exponential-related function (IF-TOPSIS $\mathrm{EF}_{\mathrm{EF}}$ ) to solve MADM problems in which the performance ratings are expressed in intuitionistic fuzzy sets (IFSs). The main advantage of this new approach is that the exponential-related function is able to represent the aggregated effect of the positive and negative evaluations in the performance ratings of the alternatives based on the intuitionistic fuzzy set (IFS) data. It also serves as a mean for the computations of the separation measures of each alternative from the intuitionistic fuzzy positive and negative ideal solutions to determine the relative closeness coefficients.

The rest of this paper is organized as follows. In Section 2, the concepts of IFS and the exponential-

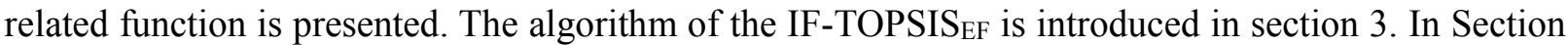
4 a numerical case is presented to illustrate the proposed approach, while some concluding remarks are presented in section 5 .

\section{Preliminaries}

In this section, the fundamental definitions and concepts of IFS theory as described by Despic and Simonovic (2000) is presented, also, the exponentially related function is introduced.

\subsection{Intuitionistic Fuzzy Set (IFS)}

\section{Definition 1}

Consider a fuzzy set $A$ in $X=\{x\}$ which is given by $A=\left\{\left\langle x, \mu_{A}(x)\right\rangle \mid x \in X\right\}$. Where $\mu_{A}: X \rightarrow[0,1]$ is the membership function of the fuzzy set $A ; \mu_{A}(x) \in[0,1]$ is the membership of $x \in X$ in $A$. since IFS is characterized by two functions which expresses the degree of membership and non-membership of an element $x$ to the set $A$, then an IFS $A$ in $X=\{x\}$ is defined as $A=\left\{\left\langle x, \mu_{A}(x), v_{A}(x)\right\rangle \mid x \in X\right\}$, where $\mu_{A}: X \rightarrow[0,1]$ and $v_{A}: X \rightarrow[0,1]$ they are defined in a way that $0 \leq \mu_{A}(x)+v_{A}(x) \leq 1, \forall x \in X$. 
The numbers $\mu_{A}(x)$ and $v_{A}(x)$ denotes the degree of membership and degree of non-membership of element $x \in[0,1]$ to the set $A$ respectively. Also, the number $\pi_{A}(x)=1-\left(\mu_{A}(x)+v_{A}(x)\right)$ which is called the intuitionistic index of $x$ in $A$ is referred to as a measure of the degree of hesitancy of element $x \in[0,1]$ in $\operatorname{set} A$. It should be noted that $0 \leq \pi_{A}(x) \leq 1$ for each $x \in X$.

\section{Definition 2}

If the IFS $A$ in $X=\{x\}$ is defined fully in the form $A=\left\{\left\langle x, \mu_{A}(x), v_{A}(x), \pi_{A}(x)\right\rangle \mid x \in X\right\}$, where $\mu_{A}: X \rightarrow[0,1], v_{A}: X \rightarrow[0,1]$ and $\pi_{A}: X \rightarrow[0,1]$. The different relations and operations for the IFS are shown in Eq. (1) to Eq. (4).

$$
\begin{aligned}
& A \cdot B=\left\{\left\langle x, \mu_{A}(x) \cdot \mu_{B}(x), v_{A}(x)+v_{B}(x)-v_{A}(x) \cdot v_{B}(x)\right\rangle \mid x \in X\right\} \\
& A+B=\left\{\left\langle x, \mu_{A}(x)+\mu_{B}(x)-\mu_{A}(x) \cdot \mu_{B}(x), v_{A}(x) \cdot v_{B}(x)\right\rangle \mid x \in X\right\} \\
& \lambda A=\left\{\left\langle x, 1-\left(1-\mu_{A}(x)\right)^{\lambda},\left(v_{A}(x)\right)^{\lambda}\right\rangle \mid x \in X\right\}, \lambda>0 . \\
& A^{\lambda}=\left\{\left\langle x,\left(\mu_{A}(x)\right)^{\lambda}, 1-\left(1-v_{A}(x)\right)^{\lambda}\right\rangle \mid x \in X\right\}, \lambda>0
\end{aligned}
$$

Definition 3 (Li, 2014)

Let $A=\left(\mu_{j}, v_{j}\right),(j=1,2,3, \ldots, n)$ be a collection of intuitionistic fuzzy numbers and $w=$ $\left(w_{1}, w_{2}, w_{3}, \ldots, w_{n}\right)^{T}$ be the weight vector of $A=\left(\mu_{j}, v_{j}\right),(j=1,2,3, \ldots, n)$, which should satisfy the normal conditions; $w_{j} \in[0,1]$ and $\sum_{j=1}^{n} w_{j}=1,(j=1,2,3, \ldots, n)$. The intuitionistic fuzzy weighted averaging (IFWA) operator is therefore defined as;

$$
\operatorname{IFWA}\left(d_{1} d_{2} d_{3}, \ldots, d_{n}\right)=\sum_{j=1}^{n} w_{j} d_{j}=\left(1-\prod_{j=1}^{n}\left(1-\mu_{j}\right)^{w_{j}}, \quad \prod_{k=1}^{n} v_{j}{ }^{w_{j}}\right)
$$

The following makes comparisons between two IFS, by introducing some metric methods by following the score function and accuracy functions.

Definition 3 (Chen \& Tan, 1994; Hong \& Choi, 2000; Xu, 2007)

Let $A=(\mu, v)$ be an intuitionistic fuzzy number, a score function $S$ and an accuracy function $H$ of an intuitionistic fuzzy value can be represented as follow.

$$
\begin{aligned}
& S(A)=(\mu-v), \text { where } S(A) \in[-1,+1] . \\
& H(A)=(\mu+v), \text { where } H(A) \in[0,1]
\end{aligned}
$$

Definition $4(\mathrm{Wu}, 2015)$

Let $A=(\mu, v)$ be the intuitionistic fuzzy number, according to $\mathrm{Wu}$ (2015) the exponential score function $S_{e}$ of the intuitionistic fuzzy number can be represented as;

$$
S_{e}(A)=e^{(\mu-v)}, \text { where } S_{e}(A) \in[1 / e, e]
$$




\subsection{The Exponential Related Function (ER)}

\section{Definition 5}

Let $A=(\mu, v)$ be the intuitionistic fuzzy number. The new exponential-related function $E R$ of the intuitionistic fuzzy number can be defined as;

$$
E R(A)=e^{\left(\frac{1-\mu^{2}-v^{2}}{3}\right)}, \text { where } E R(A) \in[1 / e, e]
$$

Theorem 1: Let $A=(\mu, v)$ and $B=\left(\mu_{1}, v_{1}\right)$ be two intuitionistic fuzzy sets. if $A \subseteq B$ then $E R(A) \leq$ $E R(B)$.

Proof: Assume that $A=(\mu, v)$ and $B=\left(\mu_{1}, v_{1}\right)$ are two comparable alternatives with intuitionistic fuzzy numbers based on some criteria $c_{i}$ such that $A \subseteq B$ without loss of generality, let assume that $\mu_{1}{ }^{2} \leq \mu^{2}$, and $v^{2} \geq v_{1}{ }^{2}$ such that $E R(A) \leq E R(B)$.

By Definition 5, we have $E R(A)=e^{\left(\frac{1-\left(\mu^{2}-v^{2}\right)}{3}\right)}$, and $E R(B)=e^{\left(\frac{1-\left(\mu_{1}^{2}-v_{1}^{2}\right)}{3}\right)}$.

If we assume $E R(B) \leqslant(A)$, we can assume $E R(B)$ can be subtracted from $E R(A)$. Therefore;

$$
\begin{aligned}
& E R(A)-E R(B)=e^{\left(\frac{1-\left(\mu^{2}-v^{2}\right)}{3}\right)}-e^{\left(\frac{1-\left(\mu_{1}^{2}-v_{1}{ }^{2}\right)}{3}\right)}=e^{\left(\frac{1-\mu^{2}-v^{2}-1+\mu_{1}^{2}+v_{1}^{2}}{3}\right)} . \text { Since, } A \subseteq B, \\
& \mu_{1}^{2} \geq \mu^{2}, \text { and } v^{2} \leq v_{1}^{2} \text { hence, }\left(\mu_{1}^{2}-\mu^{2}\right) \geq 0 \text {, or }\left(v_{1}^{2}-v^{2}\right) \leq 0, \\
& E R(B) \geq E R(A) .
\end{aligned}
$$

Definition 6: Let $A=(\mu, v)$ and $B=\left(\mu_{1}, v_{1}\right)$ be two intuitionistic fuzzy set, then the exponential related function $E R$ has the following properties;

1. If $E R(A)<E R(B)$, then $A$ is smaller than $B$ and is denoted by $A<B$,

2. If $E R(A)>E R(B)$, then $A$ is larger than $B$ and is denoted by $A>B$,

3. If $E R(A)=E R(B)$, then $A$ is equivalent to $B$ and is denoted by $A \sim B$.

\section{Algorithm of the IF-TOPSIS model based on Exponential-Related Function (IF-TOPSIS EF$_{\text {) }}$}

Consider a problem where a set of alternatives $A=\left\{A_{1}, A_{2}, A_{3}, \ldots, A_{m}\right\}$ are assessed with respect to the attributes denoted by $C=\left\{C_{1}, C_{2}, C_{3}, \ldots, C_{m}\right\}$. The characteristics of the alternative $A_{i}$ with respect to an attribute $C_{j}$ are defined first with linguistic variables and then converted to an IFS values $x_{i j}=$ $\left(\mu_{i j}, v_{i j}\right)(i=1,2, \ldots, m, j=1,2, \ldots, n)$, which represents the membership, non-membership and hesitancy degree of the alternative $A_{i} \in A$ with respect to the attribute $C_{j} \in C$ for the intuitionistic fuzzy concept. The algorithm of the IF-TOPSIS $\mathrm{EF}_{\mathrm{EF}}$ is given in following steps;

Step 1: Set up a group of Decision Makers (DMs) and aggregate their evaluations using IFWA operator; Once the DMs have given their judgments using linguistic variables, the variables are expressed using the intuitionistic fuzzy number (IFNs) as shown in Table 1 . The weight vector $\omega=\left(\omega_{1}, \omega_{2}, \omega_{3}, \ldots, \omega_{l}\right)^{T}$ is then used to aggregate all the DMs individual assessment matrices $D^{k}(k=1,2,3, \ldots, l)$ into the group 
assessment matrix (i.e. intuitionistic fuzzy decision matrix) $R_{m x n}\left(x_{i j}\right)$;

$$
R_{m \times n}\left(a_{i j}\right)=\left[\begin{array}{cccc}
\left(\mu_{11}, v_{11}\right) & \left(\mu_{12}, v_{12}\right) & \cdots & \left(\mu_{1 n}, v_{1 n}\right) \\
\left(\mu_{21}, v_{21}\right) & \left(\mu_{22}, v_{22}\right) & \cdots & \left(\mu_{2 n}, v_{2 n}\right) \\
\vdots & \vdots & \ddots & \vdots \\
\vdots & \vdots & \ddots & \vdots \\
\left(\mu_{m 1}, v_{m 1}\right) & \left(\mu_{m 2}, v_{m 2}\right) & \cdots & \left(\mu_{m n}, v_{m n}\right)
\end{array}\right]
$$

where $\mu_{i j}=1-\prod_{j=1}^{\mathrm{n}}\left(1-\mu_{j}\right)^{w_{j}}, v_{i j}=\prod_{k=1}^{n} v_{j}{ }^{w_{j}}$

Table 1

Fuzzy numbers for approximating the linguistic variable

\begin{tabular}{ll}
\hline Linguistic terms & Intuitionistic fuzzy number \\
\hline Very low $(\mathrm{VL})$ & $(0.30,0.40)$ \\
Low $(\mathrm{L})$ & $(0.50,0.50)$ \\
Good $(\mathrm{G})$ & $(0.50,0.60)$ \\
High $(\mathrm{H})$ & $(0.70,0.80)$ \\
Excellent $(\mathrm{EX})$ & $(0.90,0.90)$ \\
\hline
\end{tabular}

Step 2: Using the exponential related function $E R$ (i.e. Eq. (9)) convert the intuitionistic fuzzy decision matrix $R_{m x n}\left(x_{i j}\right)$ to form the exponential related matrix $E R M_{m x n}\left(E R_{i j}\left(a_{i j}\right)\right)$ which represents the aggregated effects of the positive and negative evaluations in the performance ratings of the alternatives based on the intuitionistic fuzzy set (IFS) data;

$$
E R M_{m x n}\left(E_{i j}\left(a_{i j}\right)\right)=\left[\begin{array}{cccc}
E R_{11}\left(x_{11}\right) & E R_{12}\left(x_{12}\right) & \ldots & E R_{1 n}\left(x_{1 n}\right) \\
E R_{22}\left(x_{22}\right) & E R_{22}\left(x_{22}\right) & \cdots & E R_{2 n}\left(x_{2 n}\right) \\
\vdots & \vdots & \ddots & \vdots \\
\vdots & \vdots & \ddots & \vdots \\
E R_{m 1}\left(x_{m 1}\right) & E R_{m 2}\left(x_{m 2}\right) & \cdots & E R_{m n}\left(x_{m n}\right)
\end{array}\right]
$$

Step 3: Define the intuitionistic fuzzy positive ideal solution (IFPIS) $A^{+}=\left(\mu_{j}, v_{j}\right)$ and the intuitionistic fuzzy negative ideal solution (IFNIS) $A^{-}=\left(\mu_{j}, v_{j}\right)$; for the exponential related functionbased matrix; $A^{+}=\left\{\left\langle C_{j},[1,1]\right\rangle \mid C_{j} \in C\right\}, A^{-}=\left\{\left\langle C_{j},[0,0]\right\rangle \mid C_{j} \in C\right\}, j=1,2,3, \ldots, n$.

Step 4: Compute the exponential related $E R$ function-based separation measures in intuitionistic fuzzy environment $\left(d^{+}{ }_{i}\left(A^{+}, A_{i}\right)\right.$ and $\left(d^{-}{ }_{i}\left(A^{-}, A_{i}\right)\right.$ for each alternative for the IFPIS and IFNIS.

$$
\begin{aligned}
& d_{i}^{+}\left(A^{+}, \quad A_{i}\right)=\sqrt{\sum_{i=1}^{n}\left[w_{j}\left(1-\left(E R M_{n x m}\left(a_{i j}\right)\right)\right]^{2}\right.} \\
& d^{-}{ }_{i}\left(A^{-}, A_{i}\right)=\sqrt{\sum_{i=1}^{n}\left[w_{j}\left(E R M_{n x m}\left(a_{i j}\right)\right)\right]^{2}}
\end{aligned}
$$

where $w_{j}$ is the weight of the criteria. 
Step 5: Compute the relative closeness coefficient, $\left(C C_{i}\right)$, which is defined to rank all possible alternatives with respect to the positive ideal solution $A^{+}$. The general formula is given as;

$$
C C_{i}=\frac{d^{-}{ }_{i}\left(A^{-}, A_{i}\right)}{d^{-}{ }_{i}\left(A^{-}, A_{i}\right)+d^{+}{ }_{i}\left(A^{+}, A_{i}\right)}
$$

where $C C_{i}(i=1,2, \ldots n)$ is the relative closeness coefficient of $A_{i}$ with respect to the positive ideal solution $A^{+}$and $0 \leq C C_{i} \leq 1$.

Step 6: Rank the alternatives in the descending order.

\section{Illustrative Examples}

In this section, we demonstrate the results of the implementation of the IF-TOPSIS EF $_{\text {method for }}$ solving MADM problems by using a real life case study (Case 1) which is based on the evaluation of concept designs of a part in an HDD machine (The drill pipe slider), and for some hypothetical examples to show the effectiveness of the proposed approach.

Case 1: An HDD machine is a key equipment for trenchless construction, which is used widely in infrastructure installation in different areas, e.g. telecommunications, natural gas, drainage lines and electric installations'.

In this case, a major part of the machine have been identified for redesign (The drill pipe slider), and four design concepts, namely $A_{1}, A_{2}, A_{3}$, and $A_{4}$, have been generated for the drill pipe slider during the conceptual design phase by the product development team of design company in Malaysia, and they are to be evaluated with respect to the attributes; AA (ability and adaptability to different temperature and altitude), PR (parts reliability), AS (appearance and structure) and SC (self-control ability) which have the following weights values $W=\{0.15,0.25,0.40,0.35\}$ respectively.

Three DMs $d^{k}(k=1,2,3)$ from the product development unit, technical management team and manufacturing are involved in the design concept evaluation. Due to the difference in their experience and expertise, they are associated with the weighting vector $\lambda=(0.35,0.30,0.25)^{T}$. Using the intuitionistic fuzzy decision matrices $d^{k}(k=1,2,3)$ given by the three DMs, which were achieved using linguistic variables (see Table 2) and then the intuitionistic fuzzy numbers (IFNs), we evaluate the design concept with the proposed method.

Table 2

DMs ratings using linguistic variables

\begin{tabular}{|c|c|c|c|c|c|c|c|c|c|c|c|c|}
\hline $\mathrm{C}_{\mathrm{i}}$ & E1 & E2 & E3 & E1 & E2 & E3 & E1 & E2 & E3 & E1 & $\mathrm{E} 2$ & E3 \\
\hline & \multicolumn{3}{|c|}{$\mathrm{AA}$} & \multicolumn{3}{|c|}{ PR } & \multicolumn{3}{|c|}{$\mathrm{AS}$} & \multicolumn{3}{|c|}{$\mathrm{SC}$} \\
\hline $\mathrm{A} 1$ & $\mathrm{~L}$ & G & VL & $\mathrm{H}$ & $\mathrm{L}$ & $\mathrm{H}$ & VL & $\mathrm{H}$ & $\mathrm{G}$ & $\mathrm{G}$ & $\mathrm{L}$ & VL \\
\hline A2 & $\mathrm{H}$ & $\mathrm{H}$ & VL & EX & $\mathrm{L}$ & EX & $\mathrm{L}$ & EX & $\mathrm{H}$ & VL & G & $\mathrm{L}$ \\
\hline A3 & EX & EX & $\mathrm{L}$ & VL & $\mathrm{H}$ & $\mathrm{H}$ & G & $\mathrm{H}$ & EX & $\mathrm{L}$ & $\mathrm{H}$ & G \\
\hline A4 & $\mathrm{H}$ & $\mathrm{H}$ & G & $\mathrm{L}$ & G & G & $\mathrm{L}$ & $\mathrm{L}$ & VL & G & $\mathrm{L}$ & VL \\
\hline$d^{1}=$ & {$\left[\begin{array}{l}(0.50, \\
(0.70, c \\
(0.90, c \\
(0.70,\end{array}\right.$} & $\begin{array}{l}0) \\
0) \\
0) \\
0)\end{array}$ & $\begin{array}{l}(0.70,0.80) \\
(0.90,0.90) \\
(0.30,0.40]) \\
(0.50,0.50)\end{array}$ & $\begin{array}{l}(0.3 \\
(0.5 \\
(0.5 \\
(0.5\end{array}$ & $\begin{array}{l}0.40) \\
0.50) \\
0.60) \\
0.50)\end{array}$ & $\begin{array}{l}(0.50, \\
(0.30, \\
(0.50, \\
(0.50,\end{array}$ & & & & & & \\
\hline
\end{tabular}




$$
\begin{array}{r}
d^{2}=\left[\begin{array}{llll}
(0.50,0.60) & (0.50,0.50) & (0.70,0.80) & (0.50,0.50) \\
(0.70,0.80) & (0.50,0.50) & (0.90,0.90) & (0.50,0.60) \\
(0.90,0.90) & (0.70,0.80) & (0.70,0.80) & (0.70,0.80) \\
(0.70,0.80) & (0.50,0.60) & (0.50,0.50) & (0.50,0.50)
\end{array}\right] \\
d^{3}=\left[\begin{array}{llll}
(0.30,0.40) & (0.70,0.80) & (0.50,0.60) & (0.30,0.40) \\
(0.30,0.40) & (0.90,0.90) & (0.70,0.80) & (0.50,0.50) \\
(0.90,0.90) & (0.70,0.80) & (0.90,0.90) & (0.50,0.60) \\
(0.50,0.60) & (0.50,0.60) & (0.30,0.40) & (0.30,0.40)
\end{array}\right]
\end{array}
$$

By following the algorithm of the IF-TOPSIS $\mathrm{EF}_{\mathrm{EF}}$ as given in computational steps in section 3, we evaluate the four design concepts with respect to the attributes.

Steps 1: The DMs individual assessments of the four design concepts with respect to the attributes are aggregated using the IFWA operator, the final group assessment matrix which is the intuitionistic fuzzy decision matrix $R_{m x n}\left(x_{i j}\right)$ is shown in Table 3.

\section{Table 3}

Intuitionistic fuzzy decision matrix

\begin{tabular}{lcccc}
\hline & AA & PR & AS & SC \\
\hline $\mathrm{A}_{1}$ & $(0.42,0.54)$ & $(0.61,0.71)$ & $(0.48,0.60)$ & $(0.42,0.54)$ \\
$\mathrm{A}_{2}$ & $(0.58,0.69)$ & $(0.80,0.76)$ & $(0.71,0.72)$ & $(0.40,0.52)$ \\
$\mathrm{A}_{3}$ & $(0.87,0.91)$ & $(0.54,0.64)$ & $(0.69,0.76)$ & $(0.54,0.65)$ \\
$\mathrm{A}_{4}$ & $(0.62,0.76)$ & $(0.46,0.59)$ & $(0.42,0.51)$ & $(0.42,0.54)$ \\
\hline
\end{tabular}

In step 2-4, using the exponential-related function, the intuitionistic fuzzy decision matrix $R_{4 \times 3}\left(x_{i j}\right)$ is converted to form the exponential related matrix $E R M_{4 \times 3}\left(E R_{i j}\left(a_{i j}\right)\right)$ while the exponential related function-based separation measures $\left(d^{+}{ }_{i}\left(A^{+}, A_{i}\right)\right.$ and $\left(d^{-}{ }_{i}\left(A^{-}, A_{i}\right)(i=1,2, \ldots, 4)\right.$ is calculated using Eq. (12) and Eq. (13).

In step 5-6, the relative closeness coefficient $C C_{i},(i=1,2, \ldots, 4)$ to the ideal solution is calculated using Eq. (14), while the relative closeness coefficients are ranked in the descending order. The final results are shown in Table 4.

\section{Table 4}

The exponential-related matrix, the distance measures and the relative closeness coefficients of the four design concepts

\begin{tabular}{lcccccccc}
\hline & $\mathrm{AA}$ & $\mathrm{PR}$ & $\mathrm{AS}$ & $\mathrm{SC}$ & $d^{+}{ }_{i}$ & $d^{-}{ }_{i}$ & $C C_{i}$ & Ranking \\
\hline $\mathrm{A}_{1}$ & 1.197 & 1.044 & 1.147 & 1.195 & 0.095 & 0.697 & 0.880 & 3 \\
$\mathrm{~A}_{2}$ & 1.065 & 0.931 & 0.994 & 1.209 & 0.076 & 0.645 & 0.895 & 2 \\
$\mathrm{~A}_{3}$ & 0.821 & 1.102 & 0.980 & 1.102 & 0.052 & 0.627 & 0.923 & 1 \\
$\mathrm{~A}_{4}$ & 1.014 & 1.156 & 1.209 & 1.195 & 0.115 & 0.718 & 0.862 & 4 \\
\hline
\end{tabular}

From the ranking result of the four design concepts of the drill pipe slider, we can conclude therefore that the design concept $A_{3}$ is the best design with respect to the four evaluating attributes and the three DMs preference.

Case 2: Let us consider a practical MADM problem originally reported by Ye, (2010) and adopted by Liu and Ren, (2014). In this case, the original problem has been modified to make a new example, however using the same decision matrix and attributes weight. 
Consider a computer manufacturing company's manager who wish to select a preferred mouse from a group of candidates; $A_{1}, A_{2}, A_{3}$ and $A_{4}$ for a new design. A group of experts within the company makes a decision about the mouse with respect to the following attributes; Performance $\left(C_{1}\right)$, Economy $\left(C_{2}\right)$ and Appearance $\left(C_{3}\right)$ which have the following weights values $W=\{0.35,0.25,0.40\}$ respectively and they have aggregated evaluations given in Table 5. We select the preferred mouse from the group of candidates; $A_{1}, A_{2}, A_{3}$ and $A_{4}$ using IF-TOPSIS

\section{Table 5}

Intuitionistic fuzzy decision matrix

\begin{tabular}{lccc}
\hline & $\mathrm{C}_{1}$ & $\mathrm{C}_{2}$ & $\mathrm{C}_{3}$ \\
\hline $\mathrm{A}_{1}$ & $(0.45,0.35)$ & $(0.50,0.30)$ & $(0.20,0.55)$ \\
$\mathrm{A}_{2}$ & $(0.65,0.25)$ & $(0.65,0.25)$ & $(0.55,0.15)$ \\
$\mathrm{A}_{3}$ & $(0.45,0.35)$ & $(0.55,0.35)$ & $(0.55,0.20)$ \\
$\mathrm{A}_{4}$ & $(0.75,0.15)$ & $(0.65,0.20)$ & $(0.35,0.15)$ \\
\hline
\end{tabular}

Using the exponential-related function in Eq. (9), just as in case 1, the intuitionistic fuzzy decision matrix $R_{4 \times 3}\left(x_{i j}\right)$ is converted to form the exponential related matrix, and using Eq. (12) and Eq. (13), the exponential related function-based separation measures $\left(d^{+}{ }_{i}\left(A^{+}, A_{i}\right)\right.$ and $\left(d^{-}{ }_{i}\left(A^{-}, A_{i}\right)(i=\right.$ $1,2, \ldots, 4)$ are calculated, while the relative closeness coefficient $C C_{i},(i=1,2, \ldots, 4)$ to the ideal solution is calculated using Eq. (14). The final results are shown in Table 6.

Table 6

The relative closeness coefficients of the four candidates

\begin{tabular}{cccccccc}
\hline & $\mathrm{C}_{1}$ & $\mathrm{C}_{2}$ & $\mathrm{C}_{3}$ & $d^{+}{ }_{i}$ & $d^{-}{ }_{i}$ & $C C_{i}$ & Ranking \\
\hline $\mathrm{A}_{1}$ & 2.460 & 2.226 & 3.857 & 1.055 & 1.611 & 0.604 & 4 \\
$\mathrm{~A}_{2}$ & 1.822 & 1.822 & 1.822 & 0.478 & 1.058 & 0.689 & 1 \\
$\mathrm{~A}_{3}$ & 2.460 & 2.226 & 1.916 & 0.731 & 1.308 & 0.641 & 3 \\
$\mathrm{~A}_{4}$ & 1.492 & 1.733 & 2.226 & 0.469 & 1.034 & 0.688 & 2 \\
\hline
\end{tabular}

The ranking of the four candidates as shown in Table 2 is in total agreement with the results obtained in (Liu \& Ren, 2014; Ye, 2010) and given in Table 7.

Table 7

Comparison of ranking results for the case 2

\begin{tabular}{lcccccc}
\hline & Proposed Approach & Rank & (Liu \& Ren, 2014) & Rank & (Ye, 2010) & Rank \\
\hline $\mathrm{A}_{1}$ & 0.604 & 4 & 0.4989 & 4 & 0.6862 & 4 \\
$\mathrm{~A}_{2}$ & 0.689 & 1 & 0.6722 & 1 & 0.9375 & 1 \\
$\mathrm{~A}_{3}$ & 0.641 & 3 & 0.5901 & 3 & 0.8502 & 3 \\
$\mathrm{~A}_{4}$ & 0.688 & 2 & 0.6705 & 2 & 0.9311 & 2 \\
\hline
\end{tabular}

Case 3: Let us consider another practical MADM problem originally reported by Li, (2005), by modifying the original problem to make a new example. Suppose a mobile phone company wants to select a design from among the three new phone concept designs; $A_{1}, A_{2}$, and $A_{3}$. If a group of experts within the company are to make a decision about the three new phone concept designs with respect to the following attributes; Performance $\left(C_{1}\right)$, Economy $\left(C_{2}\right)$ and Appearance $\left(C_{3}\right)$ which have the following weights values $W=\{0.35,0.25,0.40\}$ respectively. If the experts aggregated evaluations are given in the Table 8 . We select the preferred new phone concept designs using IF-TOPSIS EF $_{\text {method. }}$

\section{Table 8}

Intuitionistic fuzzy decision matrix

\begin{tabular}{lccc}
\hline & $\mathrm{C}_{1}$ & $\mathrm{C}_{2}$ & $\mathrm{C}_{3}$ \\
\hline $\mathrm{A}_{1}$ & $(0.75,0.10)$ & $(0.60,0.25)$ & $(0.80,0.20)$ \\
$\mathrm{A}_{2}$ & $(0.80,0.15)$ & $(0.68,0.20)$ & $(0.45,0.50)$ \\
$\mathrm{A}_{3}$ & $(0.40,0.45)$ & $(0.75,0.05)$ & $(0.60,0.30)$ \\
\hline
\end{tabular}


Using the exponential-related function just as in case 2, the intuitionistic fuzzy decision matrix $R_{4 \times 3}\left(x_{i j}\right)$ is converted to form the exponential related matrix $E R M_{4 \times 3}\left(\operatorname{ER}_{i j}\left(a_{i j}\right)\right)$ and the exponential related function-based separation measures $\left(d^{+}{ }_{i}\left(A^{+}, A_{i}\right)\right.$ and $\left(d^{-}{ }_{i}\left(A^{-}, A_{i}\right)(i=\right.$ $1,2, \ldots, 4)$ is calculated, as well as the relative closeness coefficient $C C_{i},(i=1,2, \ldots, 3)$. The final results are shown in Table 9. The ranking of the three concept designs as shown in Table 9 is in agreement with the ranking results obtained in $(\mathrm{Li}, 2005)$.

Table 9

The exponential-related matrix, the distance measures and the relative closeness coefficients of the four candidates

\begin{tabular}{llllrrrrrl}
\hline & $\mathrm{C}_{1}$ & $\mathrm{C}_{2}$ & $\mathrm{C}_{3}$ & $d^{+}{ }_{i}$ & $d^{-}{ }_{i}$ & $C C_{i}$ & Rank & $(\mathrm{Li}, 2005)$ & Rank \\
\hline $\mathrm{A}_{1}$ & 1.161 & 1.264 & 1.143 & 0.123 & 0.707 & 0.851 & 1 & 0.7335 & 1 \\
$\mathrm{~A}_{2}$ & 1.136 & 1.212 & 1.418 & 0.173 & 0.750 & 0.813 & 3 & 0.6563 & 3 \\
$\mathrm{~A}_{3}$ & 1.416 & 1.158 & 1.275 & 0.155 & 0.734 & 0.826 & 2 & 0.6616 & 2 \\
\hline
\end{tabular}

Case 4: Finally, let us consider a practical failure detection problem originally presented by Chang and Wen (2010) and adopted by Liu et al. (2015), to make a new example for early product design reliability assessment.

Suppose a design company wants to identify to-be-improved product components in a complex product in which the components are interdependent on each other, if sixteen operational components $\mathrm{A}_{\mathrm{i}}(i=1,2, . .16)$ are identified through customer survey and through the historical failure data of the product. The components are evaluated by three experts with equal expertise, where the failure modes in the sixteen operational components are evaluated with respect to three attributes; Severity, Occurrence and Detection which have the following weights values $W=$ $\{0.232,0.349,0.419\}$ respectively. If the experts aggregated evaluations are given as shown in Table 10. Then we evaluate the failure modes using the IF-TOPSIS $\mathrm{EF}_{\mathrm{F}}$ method.

Table 10

Intuitionistic fuzzy decision matrix for the Product Components

\begin{tabular}{llll}
\hline Components & Severity & Occurrence & Detection \\
\hline C1 & $(0.337,0.543)$ & $(0.566,0.290)$ & $(0.386,0.516)$ \\
C2 & $(0.380,0.514)$ & $(0.467,0.467)$ & $(0.418,0.495)$ \\
C3 & $(0.421,0.490)$ & $(0.645,0.204)$ & $(0.124,0.739)$ \\
C4 & $(0.519,0.383)$ & $(0.472,0.464)$ & $(0.373,0.519)$ \\
C5 & $(0.329,0.548)$ & $(0.540,0.344)$ & $(0.244,0.636)$ \\
C6 & $(0.235,0.626)$ & $(0.540,0.344)$ & $(0.277,0.598)$ \\
C7 & $(0.129,0.733)$ & $(0.623,0.218)$ & $(0.148,0.715)$ \\
C8 & $(0.171,0.678)$ & $(1.000,0.000)$ & $(0.240,0.629)$ \\
C9 & $(0.472,0.464)$ & $(0.495,0.413)$ & $(0.161,0.696)$ \\
C10 & $(0.579,0.268)$ & $(0.556,0.312)$ & $(0.519,0.383)$ \\
C11 & $(0.279,0.587)$ & $(0.553,0.335)$ & $(0.337,0.543)$ \\
C12 & $(0.400,0.500)$ & $(0.606,0.256)$ & $(0.358,0.528)$ \\
C13 & $(0.287,0.582)$ & $(0.636,0.208)$ & $(0.532,0.377)$ \\
C14 & $(0.306,0.563)$ & $(0.524,0.371)$ & $(0.232,0.635)$ \\
C15 & $(0.421,0.490)$ & $(0.522,0.400)$ & $(0.051,0.822)$ \\
C16 & $(0.376,0.520)$ & $(0.447,0.477)$ & $(0.358,0.528)$ \\
\hline
\end{tabular}

Using the exponential-related function, the intuitionistic fuzzy decision matrix $R_{16 \times 3}\left(a_{i j}\right)$ is converted to form the exponential related matrix $E_{R M_{16 x 3}}\left(E R_{i j}\left(a_{i j}\right)\right)$ and following the implementation procedure just as in the previous cases, we compute the exponential related function-based separation 
measures $\left(d^{+}{ }_{i}\left(A^{+}, A_{i}\right)\right.$ and $\left(d^{-}{ }_{i}\left(A^{-}, A_{i}\right)(i=1,2, \ldots, 16)\right.$, and the relative closeness coefficient $C C_{i},(i=1,2, \ldots, 16)$ to the ideal solution. The final results are shown in Table 11.

Table 11

The exponentially related matrix, the distance measures and the relative closeness coefficients of the failure modes for the product components

\begin{tabular}{llllrrrl}
\hline \multirow{2}{*}{ Components } & $\begin{array}{l}\text { Severity } \\
\text { ER }\end{array}$ & $\begin{array}{l}\text { Occurrence } \\
\text { ER }\end{array}$ & $\begin{array}{l}\text { Detection } \\
\text { ER }\end{array}$ & $d^{+}{ }_{i}$ & $d^{-}{ }_{i}$ & \multirow{2}{*}{$C C_{i}$} & Rank \\
\hline C1 & 1.483 & 1.290 & 1.451 & 0.244 & 0.822 & 0.771 & 5 \\
C2 & 1.452 & 1.396 & 1.429 & 0.247 & 0.829 & 0.770 & 6 \\
C3 & 1.425 & 1.232 & 1.666 & 0.297 & 0.865 & 0.744 & 14 \\
C4 & 1.340 & 1.392 & 1.458 & 0.239 & 0.819 & 0.774 & 3 \\
C5 & 1.488 & 1.317 & 1.566 & 0.281 & 0.858 & 0.753 & 9 \\
C6 & 1.561 & 1.317 & 1.533 & 0.283 & 0.861 & 0.752 & 10 \\
C7 & 1.660 & 1.246 & 1.643 & 0.326 & 0.896 & 0.733 & 15 \\
C8 & 1.611 & 1.000 & 1.562 & 0.283 & 0.833 & 0.746 & 13 \\
C9 & 1.392 & 1.361 & 1.626 & 0.293 & 0.868 & 0.748 & 12 \\
C10 & 1.278 & 1.300 & 1.340 & 0.182 & 0.763 & 0.807 & 1 \\
C11 & 1.525 & 1.308 & 1.483 & 0.262 & 0.840 & 0.762 & 8 \\
C12 & 1.438 & 1.262 & 1.467 & 0.238 & 0.815 & 0.774 & 3 \\
C13 & 1.520 & 1.237 & 1.332 & 0.214 & 0.789 & 0.787 & 2 \\
C14 & 1.503 & 1.333 & 1.568 & 0.286 & 0.864 & 0.751 & 11 \\
C15 & 1.425 & 1.344 & 1.747 & 0.335 & 0.905 & 0.730 & 16 \\
C16 & 1.457 & 1.409 & 1.467 & 0.261 & 0.842 & 0.764 & 7 \\
\hline
\end{tabular}

To demonstrate the effectiveness of the IF-TOPSIS $S_{\mathrm{EF}}$ method for MADM problems, we compare the results of the example by analyzing the case with some similar computational approaches including the fuzzy TOPSIS model by Braglial et al. (2003), the integrated weight-based fuzzy TOPSIS (IWFTOPSIS) by Song et al. (2013), the intuitionistic fuzzy hybrid TOPSIS (IFH-TOPSIS) approach by Liu et al. (2015) and the risk priority number (RPN) method. The final ranking results are shown in Table 12.

Table 12

Comparison of the ranking results using the different approaches

\begin{tabular}{llllll}
\hline Components & Proposed Model & Fuzzy TOPSIS model & IWF-TOPSIS & IFH-TOPSIS & RPN method \\
\hline C1 & 5 & 9 & 10 & 7 & 6 \\
C2 & 6 & 13 & 8 & 9 & 10 \\
C3 & 14 & 4 & 5 & 5 & 9 \\
C4 & 3 & 6 & 2 & 6 & 3 \\
C5 & 9 & 11 & 11 & 11 & 14 \\
C6 & 10 & 15 & 14 & 15 & 10 \\
C7 & 15 & 16 & 16 & 16 & 15 \\
C8 & 13 & 2 & 15 & 4 & 13 \\
C9 & 12 & 7 & 3 & 8 & 8 \\
C10 & 1 & 1 & 1 & 1 & 1 \\
C11 & 8 & 10 & 13 & 10 & 6 \\
C12 & 3 & 3 & 4 & 3 & 4 \\
C13 & 2 & 5 & 7 & 2 & 2 \\
C14 & 11 & 14 & 12 & 14 & 10 \\
C15 & 16 & 10 & 9 & 13 & 16 \\
C16 & 7 & 15 & 6 & 12 & 5 \\
\hline & & & & & \\
\hline
\end{tabular}




\section{Conclusion}

This paper proposes a new exponential related function (ER) as a replacement for the traditional exponential score function which is only effective for determining priority weights that involve pairwise comparison. By developing an intuitionistic fuzzy TOPSIS model based on the exponentialrelated function (IF-TOPSIS $\mathrm{EF}_{\mathrm{F}}$ ) to solve Multi-attribute decision making (MADM) problems in which the performance ratings are expressed in intuitionistic fuzzy sets (IFSs).

The main advantage of the new approach is that the exponential-related function stands to represent the aggregated effect of the positive and negative evaluations in the performance ratings of the alternatives based on the intuitionistic fuzzy set (IFS) data. Also, it serves as a parameter for the computation of the separation measures of each alternative from the intuitionistic fuzzy positive and negative ideal solution to determine the relative closeness coefficient.

Finally, to demonstrate the effectiveness of the proposed method, the IF-TOPSIS $\mathrm{EF}_{\mathrm{EF}}$ has been applied for the evaluation of the concept designs of a part in an HDD machine (The drill pipe slider), and for some hypothetical examples which have been compared with some similar computational approaches. In the future, we will continue working on the application of the proposed method specifically for problems with more criteria and alternatives and integrate the approach with some attribute weight determination methods.

\section{Acknowledgment}

The authors would like to thank the anonymous reviewers.

\section{References}

Atanassov, K. T. (1986). Intuitionistic fuzzy sets. Fuzzy Sets and Systems, 20(1), 87-96. http://doi.org/10.1016/S0165-0114(86)80034-3

Bai, Z. (2013). An Interval-Valued Intuitionistic Fuzzy TOPSIS Method Based on an Improved Score Function. The Scientific World Journal, 2013, 1-9. http://doi.org/10.1155/2013/879089

Braglia1, M., Frosolini, M., \& Montanari, R. (2003). Fuzzy TOPSIS approach for failure mode, effects and criticality analysis. Quality and Reliability Engineering International, 19(5), 425-443.

Chang, K. H., \& Wen, T. C. (2010). A novel efficient approach for DFMEA combining 2-tuple and the OWA operator. Expert Systems with Applications, 37(3), 2362-2370. http://doi.org/10.1016/j.eswa.2009.07.026

Chen, S. M., \& Chiou, C. H. (2015). A new method for multiattribute decision making based on interval-valued intuitionistic fuzzy sets, PSO techniques and evidential reasoning methodology. Proceedings - International Conference on Machine Learning and Cybernetics, 1(6), 403-409. http://doi.org/10.1109/ICMLC.2014.7009149

Chen, S.-M., \& Tan, J.-M. (1994). Handling multicriteria fuzzy decision-making problems based on vague set theory. Fuzzy Sets and Systems, 67(2), 163-172.

Despic, O., \& Simonovic, S. P. (2000). Aggregation operators for soft decision making in water resources. Fuzzy Sets and Systems, 115(1), 11-33. http://doi.org/10.1016/S0165-0114(99)00030-5

Hong, D. H., \& Choi, C.-H. (2000). Multi-criteria fuzzy decision making problems based on vague set theory. Fuzzy Sets and Systems, 114(1), 103-113. http://doi.org/10.1016/S0165-0114(98)00271-1

Jahromi, M. K. (2012). Multiattribute decision making models and methods using intuitionistic fuzzy sets. International Mathematical Forum, 7(57), 2847-2851. http://doi.org/10.1016/j.jcss.2004.06.002

Li, D.-F. (2005). Multiattribute decision making models and methods using intuitionistic fuzzy sets. Journal of Computer and System Sciences, 70(1), 73-85. http://doi.org/10.1016/j.jcss.2004.06.002 
Li, D.-F. (2014). Decision and Game Theory in Management With Intuitionistic Fuzzy Sets. Studies in Fuzziness and Soft Computing, 308, 1-462. http://doi.org/10.1007/978-3-642-40712-3

Lin, L., Yuan, X. H., \& Xia, Z. Q. (2007). Multicriteria fuzzy decision-making methods based on intuitionistic fuzzy sets. Journal of Computer and System Sciences, 73(1), 84-88. http://doi.org/10.1016/j.jcss.2006.03.004

Liu, H.-C., Liu, L., \& Li, P. (2015). Failure mode and effects analysis using intuitionistic fuzzy hybrid TOPSIS approach. Soft Comput, 19, 1085-1098. http://doi.org/10.1007/s00500-014-1321-x

Liu, M., \& Ren, H. (2014). A New Intuitionistic Fuzzy Entropy and Application in Multi-Attribute Decision Making. Information, 5(4), 587-601. http://doi.org/10.3390/info5040587

Liu, P., \& Zhang, L. (2014). The Extended VIKOR Method for Multiple Criteria Decision Making Problem Based on Neutrosophic Hesitant Fuzzy Set.

Saurav Datta, Chitrasen Samantra, Siba Sankar Mahapatra, Goutam Mondal, Partha Sarathi Chakraborty, G. M. (2013). Selection of internet assessment vendor using TOPSIS method in fuzzy environment. International Journal of Business Performance and Supply Chain Modelling, 5(1), 127. http://doi.org/10.1504/IJBPSCM.2013.051645

Song, W., Ming, X., Wu, Z., \& Zhu, B. (2013). Failure modes and effects analysis using integrated weight-based fuzzy TOPSIS. International Journal of Computer Integrated Manufacturing, 26(12), 1172-1186. http://doi.org/10.1080/0951192X.2013.785027

Wan, S. P., \& Li, D. F. (2015). Fuzzy mathematical programming approach to heterogeneous multiattribute decision-making with interval-valued intuitionistic fuzzy truth degrees. Information Sciences, 325, 484-503. http://doi.org/10.1016/j.ins.2015.07.014

$\mathrm{Wu}$, J. (2015). Consistency in MCGDM Problems with Intuitionistic Fuzzy Preference Relations Based on an Exponential Score Function. Group Decision and Negotiation, 25(2), 399-420. http://doi.org/10.1007/s10726-015-9447-5

$\mathrm{Xu}, \mathrm{Z}$. (2007). Intuitionistic preference relations and their application in group decision making. Information Sciences, 177(11), 2363-2379. http://doi.org/10.1016/j.ins.2006.12.019

$\mathrm{Xu}, \mathrm{Z}$. (2014). Intuitionistic preference modeling and interactive decision making. In Studies in Fuzziness and Soft Computing (pp. 195-223). http://doi.org/10.1007/978-3-642-28403-8

$\mathrm{Xu}, \mathrm{Z}$., \& Liao, H. (2015). A survey of approaches to decision making with intuitionistic fuzzy preference relations. Knowledge-Based Systems, 80, 131-142. http://doi.org/10.1016/j.knosys.2014.12.034

$\mathrm{Xu}, \mathrm{Z}$., Member, S., \& Liao, H. (2013). Intuitionistic fuzzy analytic hierarchy process. IEEE Transactions on Fuzzy Systems, 22(4), 1. http://doi.org/10.1109/TFUZZ.2013.2272585

Ye, J. (2010). Fuzzy decision-making method based on the weighted correlation coefficient under intuitionistic fuzzy environment. European Journal of Operational Research, 205(1), 202-204. http://doi.org/10.1016/j.ejor.2010.01.019

Zadeh, L. A. (1965). Fuzzy sets. Information and Control, 8, 338-353. http://doi.org/10.1016/S00199958(65)90241-X

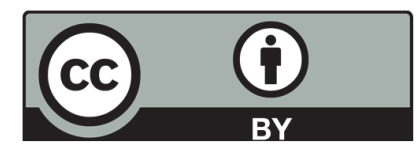

(C) 2017 by the authors; licensee Growing Science, Canada. This is an open access article distributed under the terms and conditions of the Creative Commons Attribution (CC-BY) license 